\title{
The Impact of Free Preschool Education on Educational Inequality in China
}

\author{
Ziqi Weng ${ }^{1, \#, *}$, Jiayi Tang ${ }^{2, \#, ~ K e y u ~ L i u ̈, \# ~}$ \\ ${ }^{I}$ Northfield Mount Hermon School, MA 01354, United States \\ ${ }^{2}$ Zhenhai High School of Zhejiang Cambridge A-level Center, Ningbo, Zhejiang, 315200, China \\ ${ }^{3}$ Dulwich International High School Suzhou, Suzhou, Jiangsu, 215000, China \\ \# The authors contributed equally to this manuscript \\ *Corresponding author. Email: zweng23@nmhschool.org
}

\begin{abstract}
Preschool education has the highest rate of return among all education levels, but China has only made primary and secondary education free and compulsory rather than preschools (In China, preschool and kindergarten both refer to the education of children aged 3-6. The terms are interchangeable in this paper.). In 2012, Tibet implemented a free preschool education policy. This paper uses a two-step method to evaluate the impact of this policy on educational inequality, measured by Gini coefficients of education. First, we use the difference-in-differences (DD) model to showcase the policy's impact on several intermediate factors. Then, we run a multiple linear regression to examine how the intermediate factors affect educational inequality. Finally, we apply the Chi-square goodness-of-fit test to compare different provinces' contributions to educational inequality. Results support that the free preschool education policy reduces inequality through improving faculty educational attainment and increasing kindergarten accessibility. Evidence suggests that implementation of similar free preschool education policies in Ningxia and Yunnan might further reduce inequality.
\end{abstract}

Keywords: free preschool education, educational inequality, Gini coefficient of education, China.

\section{INTRODUCTION}

"Education can be seen as an activity that adds to the stock of human capital." [1] said T.W Schultz, the first and most influential in the formative period of the human capital theory, which proves the positive relationship between education investment and future economic development. The return on human capital investment diminishes with age (i.e. the return rate is the highest for preschool education investment) [2]. Furthermore, studies show that preschool education significantly impacts children's cognitive, social and emotional skills, improves their future academic and professional achievements, and generates more savings for government expenditures $[3,4]$.

Since the reform and opening up, China has made great progress in preschool education, but a wide gap exists between preschool education and other education levels due to the nine-year compulsory education policy carried out in 1986. The lack of relevant domestic research also makes the development process more difficult. In response to the stagnant development of preschool education, this paper intends to call on society to pay more attention to preschool education in China.
Similar to the nine-year compulsory education, free preschool education has been implemented in Tibet and other provinces since 2012, which has aroused heated discussions: policymakers might worry about the enormous expenditure on preschool education, and the general public might wonder whether or not free preschools are worth it. This study uses a two-step method and three statistics models to evaluate the impact of the free preschool education policy in Tibet on interregional inequality in preschool educational opportunities.

This paper is organized as follows. Section 2 describes preschool education policies both abroad and in China, as well as the current situation and challenges of preschool education in China. Section 3 introduces the methodology and data used in the research. Section 4 showcases DD estimation results of the policy change, discusses determinants of preschool educational inequality from regression analysis, and double checks educational inequality with Chi-square test. Section 5 provides result implications and directions for further research. 


\section{BACKGROUND}

\subsection{Free preschool education policies abroad}

Aware of the impact of preschool education on future international competitiveness, a number of countries, especially the developed ones, have increased investment on preschool education and implemented different policies since the twentieth century to promote educational equality.

Finland is one of the countries with the best preschool education in the world, which puts a particular emphasis on preparing for further study. However, the release of the National Core Curriculum for Early Childhood Education and Care (ECEC) in 2018 has clarified its opposition to learning in advance. In other words, Finland discourages untimely development of young children. The concept that preschool education had better not be compulsory but free was proposed for the first time, and has been widely used as a global benchmark for preschool education thereafter [5].

Besides Finland, the Head Start program in the United States established in 1965 provides preschool education for 1 million disadvantaged children below 5 annually at no cost. The British government implemented the Sure Start program in 2000/1 to provide half-day free preschool education for disadvantaged three- and fouryear-old children. Since 2007, New Zealand has been providing 20 hours of free preschool education every week for three- and four-year-olds [6].

During this period, most of the policies aim to ensure equity in preschool educational opportunities. The actions taken by Finland and other countries had remarkable achievements [7] which had enlightened China to develop its unique preschool education system.

\subsection{Current situations and challenges in preschool education in China}

China implemented the nine-year compulsory education policy in 1986, which includes free primary and secondary education. Preschool education, however, was neither free nor compulsory, so Chinese parents have had a hard time sending their children into kindergartens. Some private kindergartens charge an extremely high price, which defer the most disadvantaged and needed children from entering [8]. Therefore, there has been absolute inequality in preschool enrollment: in 2000, the overall preschool enrollment rate in China was merely $35 \%$, while the number for primary school is $99.1 \%$. Moreover, in remote areas in Northwest and Southwest China, the poor teaching environment, conservative and outdated values, and stagnant economic development have led to serious educational inequality within China. For example, in 2010 , only $24.5 \%$ of children enrolled in preschool in Tibet, while $95 \%$ did in Zhejiang.
Since 2010, the Ministry of Education of the People's Republic of China has started selecting trial regions to provide free preschool education. In 2012, the "Document on Implementing the Policy of Free Public Preschool Education in the Tibet Autonomous Region" was approved, and free preschool education was implemented in the following fall semester. Tibet is also the first province that implemented the "Three Guarantees" policy to preschool: boarding, lodging, and tuition fees are all waived.

Similarly in Xinjiang Uyghur Autonomous Region (XUAR), according to a China Daily report, the Xinjiang government would pump an extra 810 million yuan into the expansion of kindergartens, and 450,000 rural kids in Xinjiang were expected to benefit from the program [9]. By 2017, the whole XUAR had practiced free preschool education; preschool enrollment rate increased by a remarkable $63 \%$ from $60 \%$ in 2010 to $97.5 \%$ in 2019 . Other underdeveloped provinces have partially implemented the free preschool education policy, such as Qinghai Tibetan Region and Aba Prefecture in Sichuan.

However, the implementation of free preschool education has two major challenges. First of all, although the growth rate of government expenditure on education is greater in Western China than in Eastern China [10], a wide gap still exists between the east and the west. The government would bear a larger financial burden than before.

Another challenge is the lack of a high-quality faculty body. College graduates do not have incentives to work in the kindergarten, primarily due to the low wage. Not only does the public not pay enough attention to preschool faculty quality, but the government has not made clear regulations on the treatment and supervision of preschool teachers. Consequently, some nonprofessionals might serve as preschool teachers, which reduces the overall faculty quality. Private kindergartens offer higher wages and better welfare, which attract high-quality graduates. Consequently, the shortage of teachers in western, rural areas becomes more severe [8].

This study aims to figure out whether or not the free preschool education policy has overcome the difficulties mentioned, and to discuss the most effective way to reduce educational inequality across different regions in China.

\section{METHODOLOGY AND DATA}

\subsection{Methods}

In this study, we construct a two-step method to evaluate the impact of free preschool education policy on preschool educational inequality in China. Because educational policies do not directly affect educational inequality, we will introduce several intermediate factors 
that are both affected by the policy and could have influenced educational inequality (see section 3.1.3).

First, we will use the difference-in-differences (DD) model to indicate the impact of the policy on intermediate factors. Secondly, we will use multiple linear regression to examine the influence of intermediate factors on preschool enrollment rate and educational inequality, respectively. Hence, the policy has affected several intermediate factors, some of which in turn affect educational inequality. Additionally, we will construct a chi-square test as an alternative approach to imply educational inequality, and as a cross-region comparison of provinces' contributions to educational inequality.

\subsubsection{The difference-in-differences model}

The DD model can be traced back to the mid-1800s when John Snow used it to discover how residents of London were being infected with cholera [11]. Scholars have used DD to evaluate social policies such as minimum wage laws, traffic jams, and health care policies [12-14]. The model is especially appealing because it allows for pre-existing differences between the control group and the treatment group.

When evaluating the free preschool education policy, we selected Tibet as the only province in the treatment group, because the policy has been implemented for 9 years-longer than any other provinces-for us to acquire sufficient data. In order to meet the counterfactual assumption [15], we carefully select provinces with similar economic development and without the policy into the control group, including Yunnan, Guizhou, Xinjiang, Ningxia, Jiangxi, and Guangxi.

DD estimates the difference in the intermediate factors before and after 2012, which also equals to $\beta_{3}$ in the following regression:

$$
y_{i}=\beta_{0}+\beta_{1} D_{t}+\beta_{2} D_{s}+\beta_{3}\left(D_{t} * D_{s}\right)+\varepsilon_{i}(1)
$$

where $y_{i}$ is the intermediate factor $M_{i}, D_{t}$ is the postperiod dummy variable, and $D_{s}$ is the treatment group dummy variable [16]. $D_{t}$ is 1 starting from 2013 and 0 for all other years, and $D_{s}$ is 1 for Tibet and 0 for all other provinces. We will use Eq. (1) to test the effect of the policy on the intermediate factors.

\subsubsection{EduGini coefficient}

Educational equality includes equality of educational opportunities (i.e. every child has equal access to education) fairness in the education process, and equality in education results [17]. Among all measures to indicate educational inequality, the use of Gini coefficient of education has become widespread since Thomas et al. (2001) measured educational inequality with both direct and indirect methods [18]. The direct method uses the following equation:

$$
\text { EduGini }=\frac{1}{\mu} \Sigma p_{i}\left[y_{i}-y_{j}\right] p_{j}(2)
$$

where EduGini is the Gini coefficient of education, $\mu$ is the mean of variable $y$, and $p_{i}$ and $p_{j}$ are the proportion of the population. For educational inequality of the whole population, $y_{i}$ and $y_{j}$ are years of school attainment [1820]; for educational inequality of school-age children, $y_{i}$ and $y_{j}$ are attendance rates for different education levels [21]. The value of EduGiniranges from 0 to 1, where 0 indicates absolute equality.

The indirect method uses the Lorenz curve with a cumulative percentage of the population on the $\mathrm{x}$-axis, and cumulative percentage of outcome $y$ on the $y$-axis [18]. The Gini coefficient of education is defined as the following:

\section{EduGini $=$}

$\frac{\text { Area between the Edu Lorenz curve and the } 45^{\circ} \text { line }}{0.5}$

In this study, we adopt the indirect method to measure the inequality of preschool enrollment in China. Banzragch et al. (2019) has measured the inequality of preschool attendance among different income groups in Mongolia using the Lorenz curve [21]. However, due to limitations in finding preschool attendance rates corresponding to individual household income levels, we adjust the Edu Lorenz curve by selecting 13 provinces as our sample. They are Ningxia, Zhejiang, Qinghai, Yunnan, Liaoning, Henan, Shanxi, Tibet, Xinjiang, Chongqing, Guizhou, Jiangxi, and Guangxi. These 13 provinces are selected from Northwest, Southwest, Northeast, and Southeast China, including underdeveloped and developed provinces, to represent China (Fig.1 and Fig.2). 


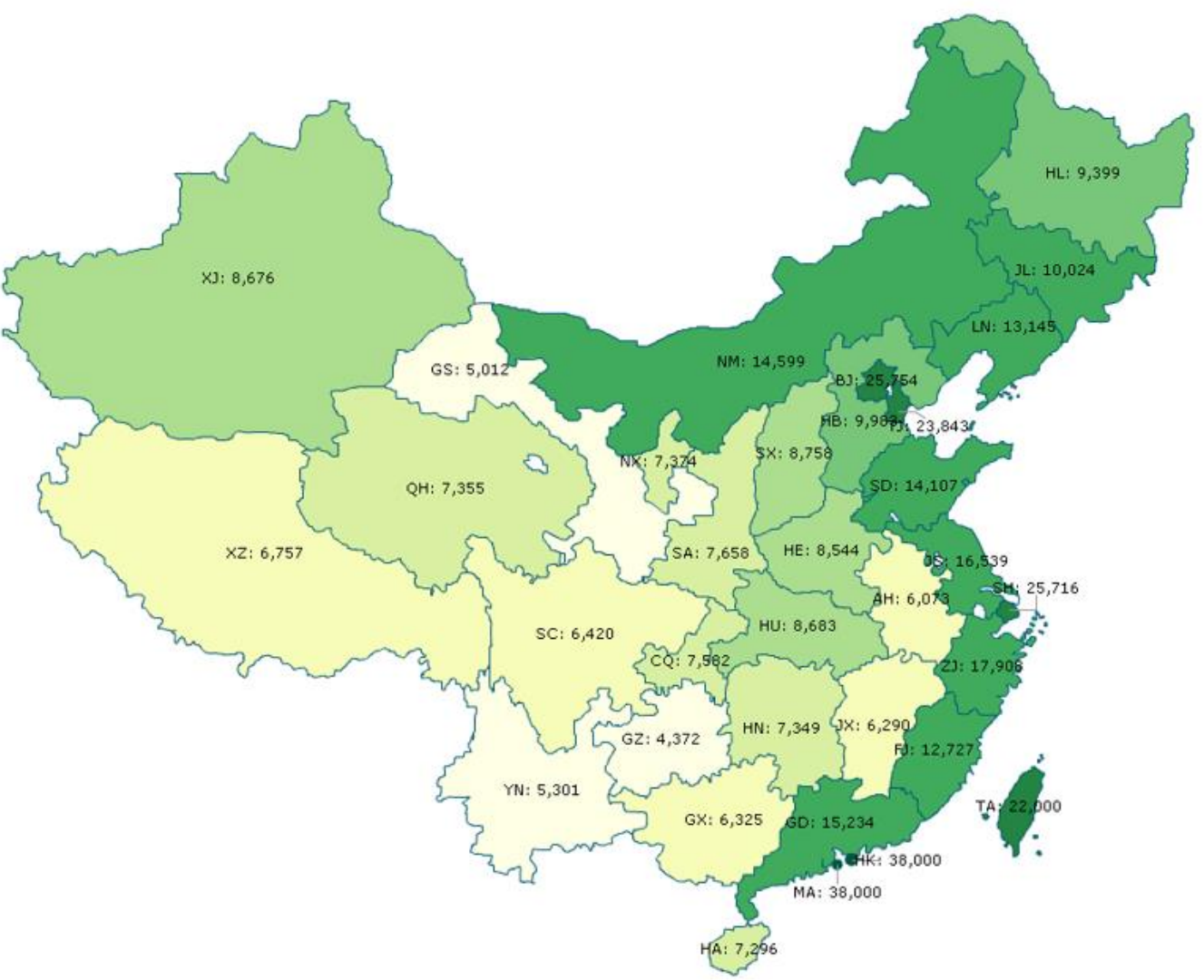

Figure 1 GDP per capita in China, 2015 ( US dollar)

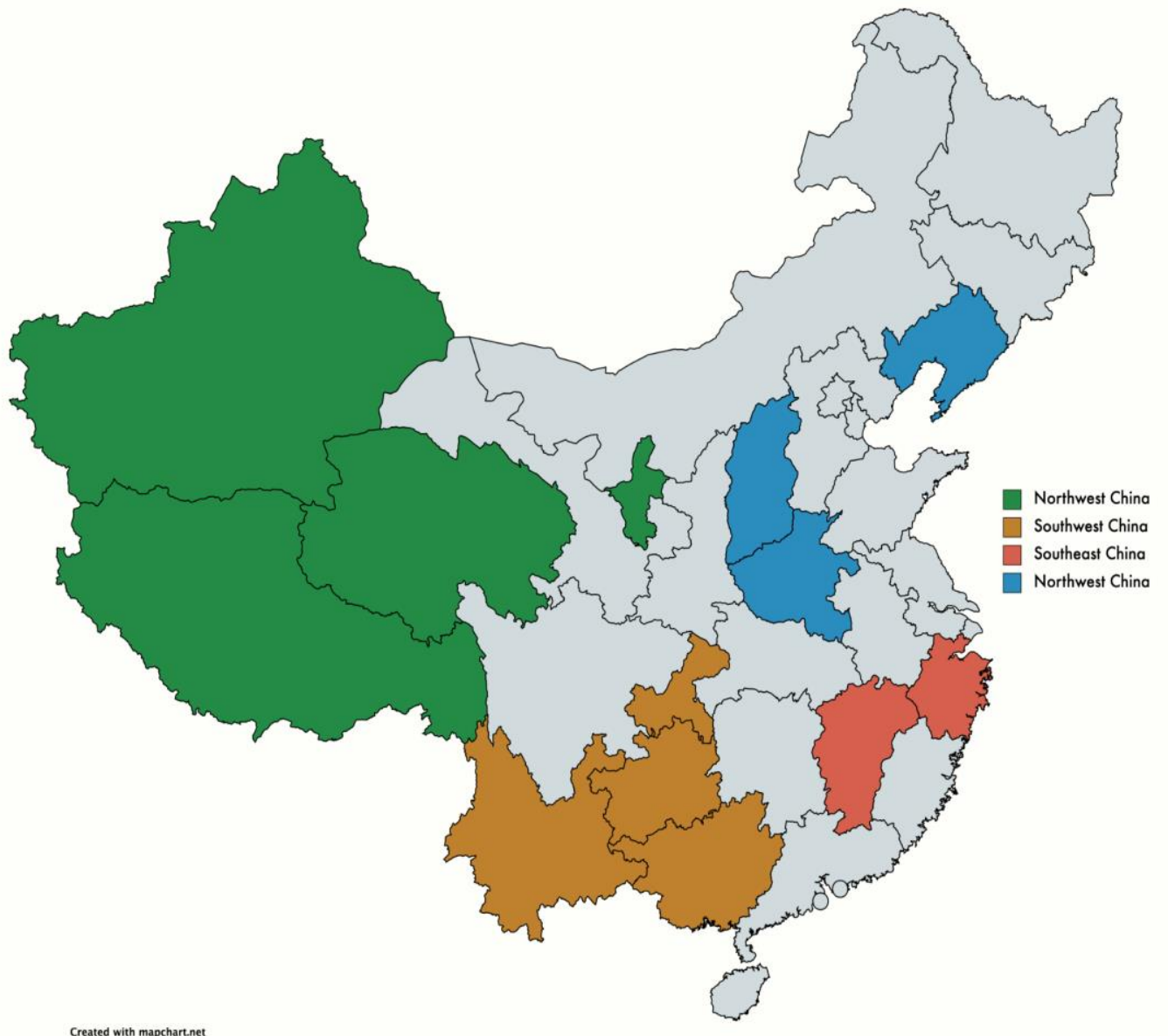

Figure 2 Sample provinces regional distribution 
Note: Xinhuibao makes Figure 1 based on China's statistical yearbooks.

On the horizontal axis, we plot the cumulative percentage of the total population, ranked by GDP per capita. On the vertical axis, we plot the cumulative percentage of the total preschool enrollment rate. For example, for province $i(1 \leq i \leq 13)$ in year $t$, the cumulative percentage of total population ( $\mathrm{x}$ value) is $\sum_{i=1}^{i} p_{i t}$, and the cumulative percentage of total preschool enrollment rate (y value) is $\sum_{i=1}^{i} p_{i t} y_{i t}$, where $p_{i t}$ is the proportion of province $i$ in year $t$, and $y_{i t}$ is the enrollment rate of province $i$ in year $t$. The 45 -degree line shows relative equality across different provinces (i.e. each province has the same enrollment rate) as well as absolute equality of China (i.e. preschool enrollment rate is $100 \%$ for all provinces). The closer to the 45 degree line, the smaller EduGini index. Preschool education opportunities in China are more evenly distributed, and the overall enrollment rate is high. The farther from the 45-degree line, the bigger EduGini index. Preschool educational opportunities are more unequal, and/or the overall preschool enrollment rate is low.

\subsubsection{Multiple Linear Regression}

Since the intermediate factors play both roles as the outcome of policy changes and as the causes of preschool enrollment, typical determinants of preschool enrollment like parental education, family income, and GDP per capita [22-24] cannot be considered. Therefore, we determine the intermediate factors first from policy plans, then from similar studies on free education in China. Because the free preschool education policy extends the nine-year compulsory education to younger children, we also review policies and research on primary and secondary school inequality. Compulsory education policies typically include free textbooks and subsidies to teachers [25]. Literature suggests that school density and education expenditure per capita are highly correlated to primary enrollment rate, while the teacher-student ratio is not [21].

Initially, we include government spending on education, the average number of books per child, kindergarten areas, kindergarten density, teacher-student ratio, and faculty education attainment as the intermediate factors. Nonetheless, when we compare books with kindergarten areas - two indicators of school resources, books per child seems to be more significant; when we compare teacher-student ratio with faculty education attainment, faculty education attainment seems to be more significant. Therefore, we exclude kindergarten areas and teacher-student ratio from our selection of intermediate factors. The multiple linear regression is formulated as in the following:

$$
Y=\gamma_{0}+\gamma_{1}(\ln (\text { govt spending }))+
$$

$$
\begin{aligned}
& \gamma_{2}(\text { faculty edu attainment })+\gamma_{3}\left(\text { books } p c^{\prime}\right) \\
& +\gamma_{4}(\text { kindergarten } p c)+\varepsilon
\end{aligned}
$$

Because teachers' average years of schooling cannot be acquired, we assign teachers with education attainment levels lower than high school weight 0 , high school graduate weight 0.25 , associate bachelor weight 0.5 , undergraduate weight 0.75 , and graduate weight 1 . Thus, faculty edu attainment ranges from 0 to 1 . books $p c^{\prime}$ is measured by dividing the number of books by the number of children enrolled, while kindergarten $p c$ is measured by dividing the number of kindergartens within a province by preschool population. Preschool population equals the number of children enrolled divided by enrollment rate.

The dependent variables are the EduGini index measured by Eq. (3) on a national level, and enrollment rate on a provincial level. We will run two multiple linear regressions using one dependent variable at each time.

\subsubsection{Chi-square test}

The Chi-square goodness-of-fit test is used to find out how the observed value of a given phenomenon is significantly different from the expected value [26]. Therefore, the chi-square test is an alternative approach to measure educational inequality. The chi-square test is constructed as the following: in a given year, observed values are actual preschool enrollment rates (measured in percentage) of the 13 provinces used in regression; expected values are $100 \%$, implying absolute equal educational opportunities. The total chi-square $\chi^{2}$ is calculated with the following equation:

$$
\chi^{2}=\Sigma \chi_{i}^{2}=\Sigma \frac{\left(O_{i}-E_{i}\right)^{2}}{E_{i}}
$$

where $\chi_{i}^{2}$ is "mini-chi-square" in province $i$, which equals to $\frac{\left(O_{i}-E_{i}\right)^{2}}{E_{i}}$. The results of the chi-square test imply the following:

1) The p-value of total chi-square indicates whether or not the actual preschool enrollment rates are different from $100 \%$, or absolute preschool educational equality in China. However, the exact inequality index cannot be calculated.

2) The proportion of "mini-chi-square," measured by $\frac{\chi_{i}^{2}}{\chi^{2}}$ indicates how much of the total chi-square statistic attributes to each individual value's difference. Comparing the contributions, we are able to identify which provinces contribute to educational inequality the most.

\subsection{Data}

This study collects the number of books, faculty education attainment, the number of kindergartens, and the number of children enrolled in each province from Educational Statistics from 2010 to 2019 from the 
Ministry of Education of the People's Republic of China. The amount of public finance budget education expenditure in each province comes from Statistical Announcement on the Implementation of National Education Funds from 2010 to 2019 from the Ministry of Education of People's Republic of China. Preschool enrollment rates in each province from 2010 to 2019 are mainly from the Statistical Bulletin of Educational Development and the National Economic and Social Development Statistical Bulletin. Lastly, the total population and GDP per capita can be accessed in the Statistical Yearbook of each province.

\section{EMPIRICAL RESULTS}

\subsection{Difference-in-differences estimates of policy impact}

Table 1 shows the impact of free preschool education policy using DD regression Eq.(1). The impact of government spending and books per child was not proven to be statistically significant at the $5 \%$ level, with pvalues of 0.52 and 0.76 , respectively, while faculty educational attainment and kindergarten density have statistically significant impact, with p-values of 0.027 and 0.003 , respectively. The latter also displays a pronounced trend of positive correlation, suggesting that Tibet after 2012 has higher faculty education attainment and kindergarten density.

Table 1 Difference-in-differences regression results for Tibet relative to other provinces

\begin{tabular}{lllll}
\hline & govt spending & books per child & $\begin{array}{l}\text { faculty education } \\
\text { attainment }\end{array}$ & kindergarten density \\
\hline DID estimate & 0.131 & -0.722 & $0.066^{* *}$ & $3.158^{* *}$ \\
& $(-0.221)$ & $(-1.118)$ & $(-0.030)$ & $(1.192)$ \\
Observations & 60 & 60 & 60 & 60 \\
R Square & 0.415 & 0.492 & 0.457 & 0.505 \\
Note. $*, * * * *$ represent significance at $10 \%, 5 \%$, and $1 \%$ level, respectively.
\end{tabular}

Therefore, Tibet's free preschool education policy improves faculty quality and school accessibility, but not government spending or resources. The results are consistent with the findings by Jiazeng Wang (2004) [22] . Fig. 3-6 visually shows the difference between Tibet and other provinces before and after 2012. The slope of the red line which represents Tibet is consistent with those of other provinces in the first two graphs but is greater than other provinces in the last two.

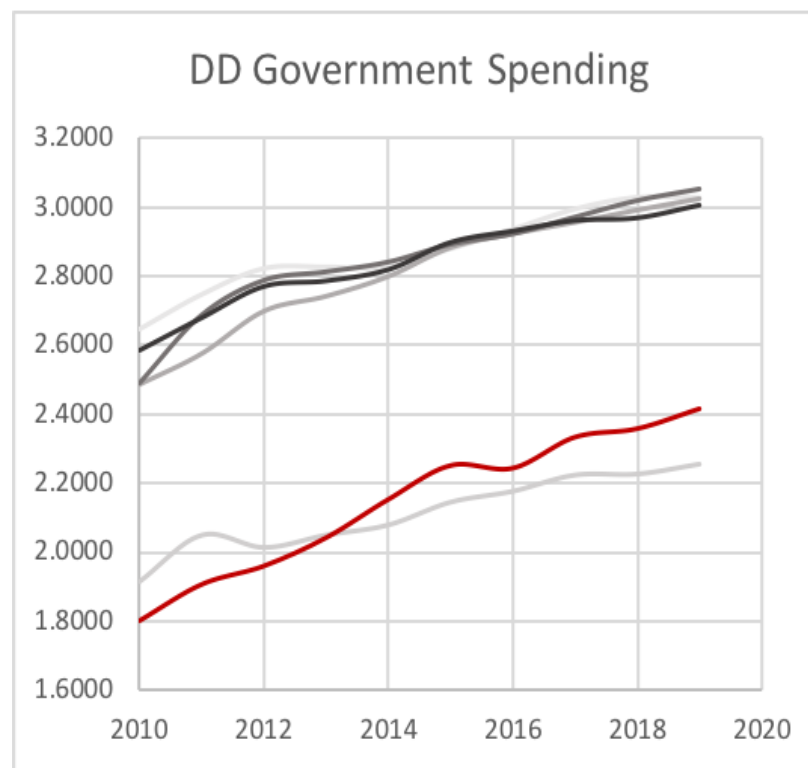

Figure 3 DD in government spending

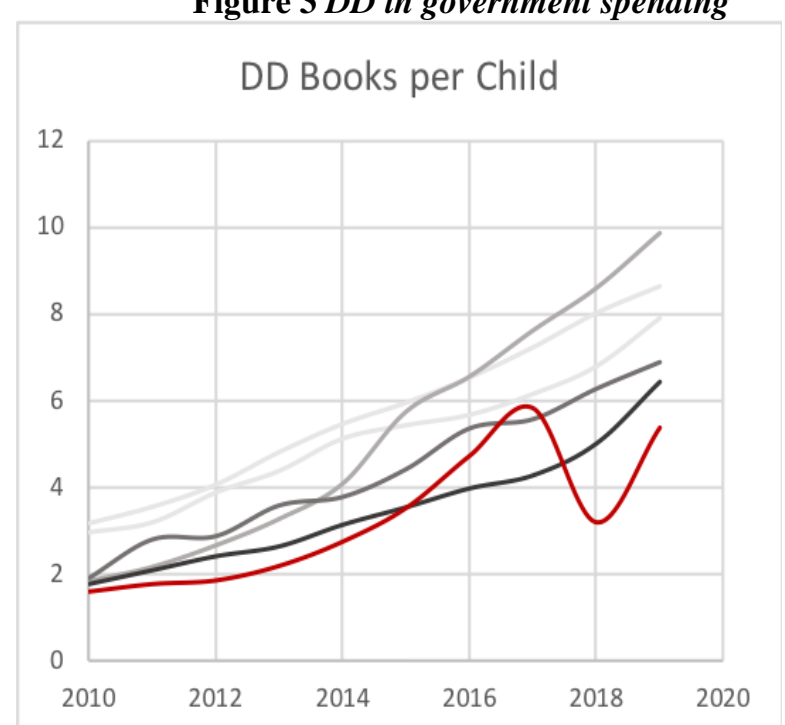

Figure 4 DD in books per child 


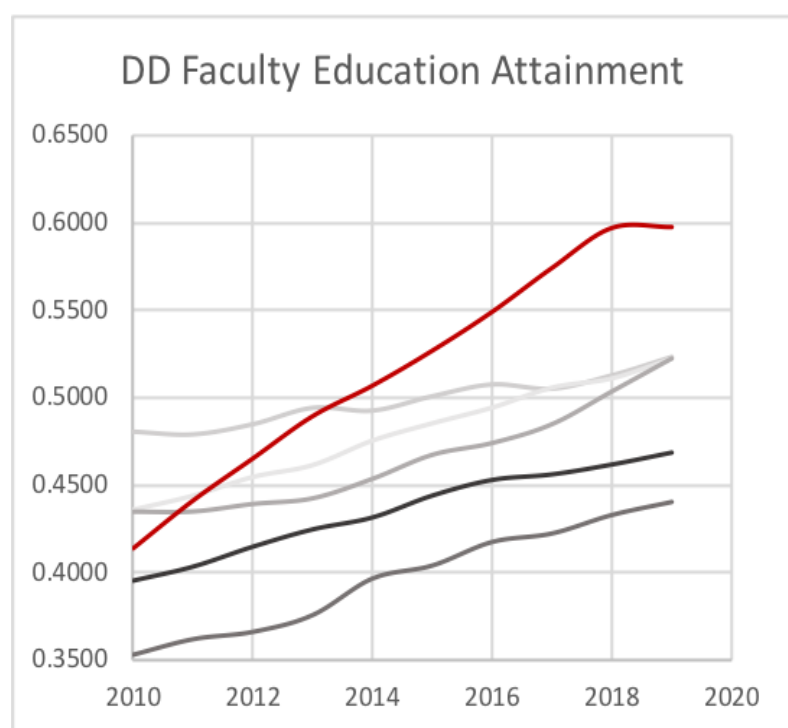

Figure 5 DD in faculty education attainment

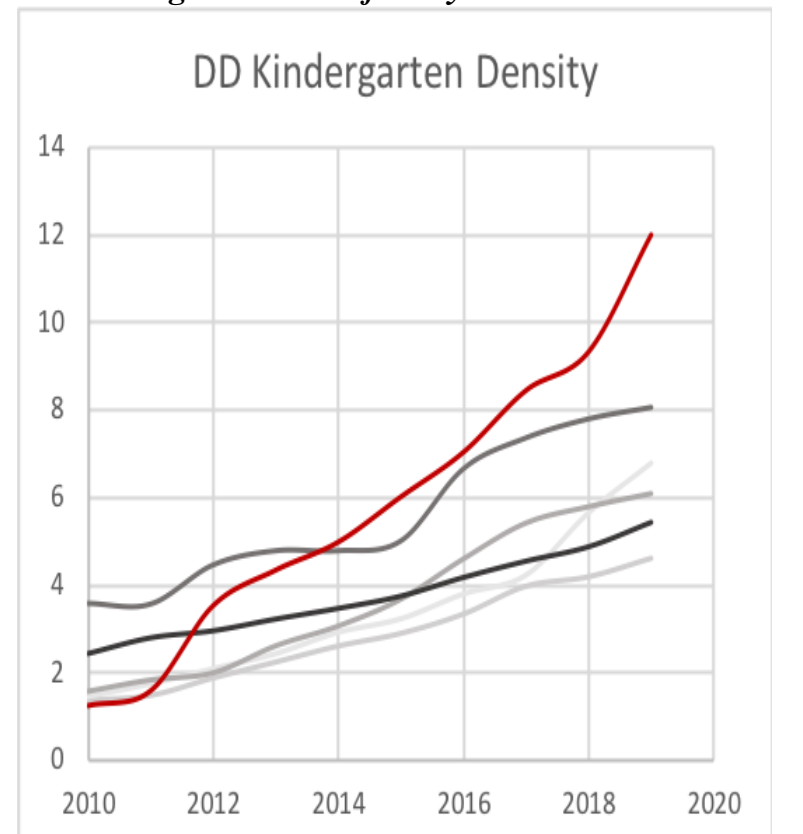

red line represents Tibet.

Government spending has not increased drastically for two possible reasons. First, government spending on free preschool education could have taken up a small proportion of total education spending. On the other hand, government spending on free preschool education could have been part of the budget, so that extra spending didn't occur after 2012. Moreover, although the number of books increased over time, children enrolled increased as well. Therefore, it is possible for the average number of books to show few differences.

An increase in faculty quality and kindergarten accessibility might be due to government regulations. For example, in 2015, the Tibet Rural Teacher Support Program required 300 outstanding graduates every year to teach in elementary schools and kindergartens for no garten density Note. The

less than 3 years. The number of kindergartens has increased tenfold since 2010.

\subsection{Educational inequality estimation and historical trend}

Fig. 7 shows the trend in the preschool EduGini index measured by preschool enrollment rate. The preschool EduGini index has reduced by $74 \%$ over 10 years, from 0.47 in 2010 to 0.12 in 2019 . In other words, equality in preschool educational opportunities improved over the past decade. In addition, the Edu Lorenz curve became flatter, indicating improvements in both relative equalities-gaps in enrollment rates across regions shrunk - and absolute equality — average enrollment rate increased by $47 \%$ over time, from $61 \%$ in 2010 to $90 \%$ in 2019. 


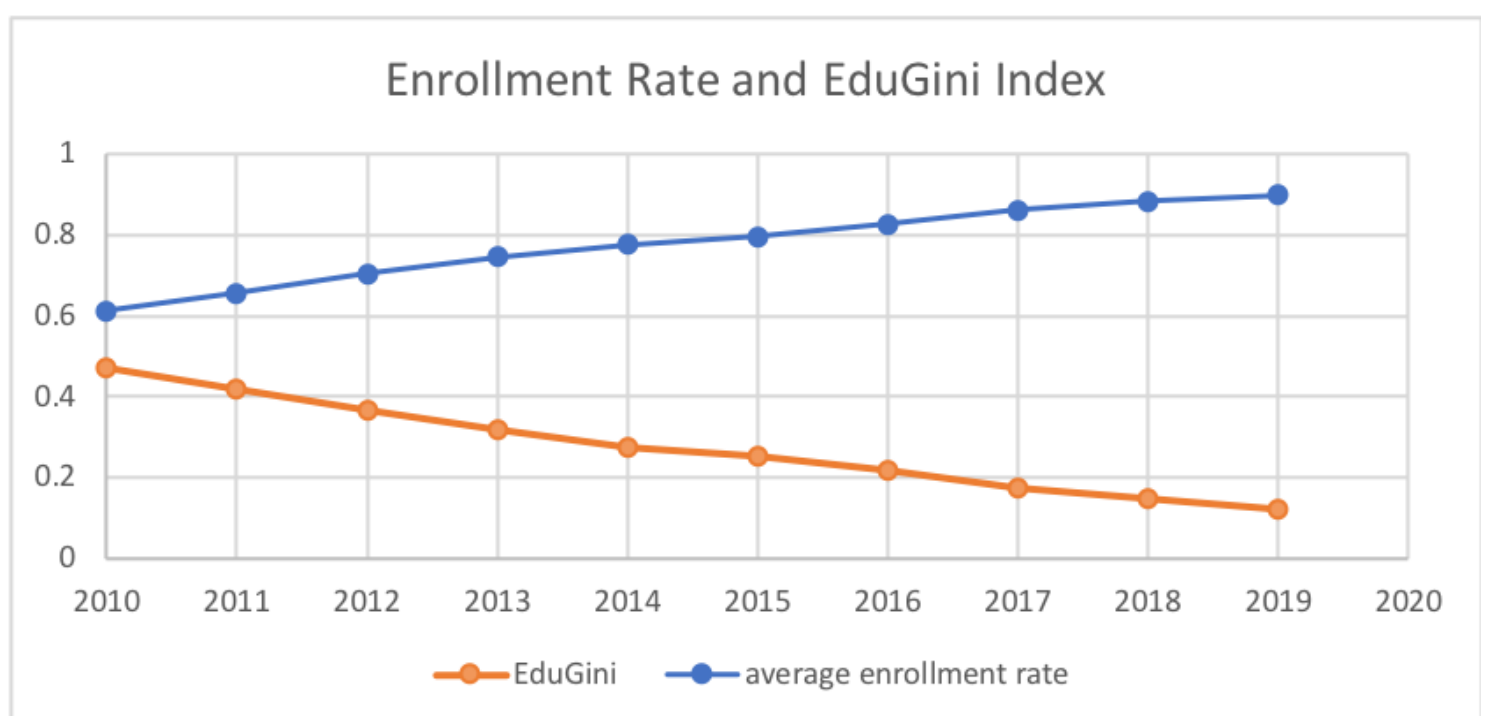

Figure 7 Average preschool enrollment rate and the EduGini index, 2010-2019

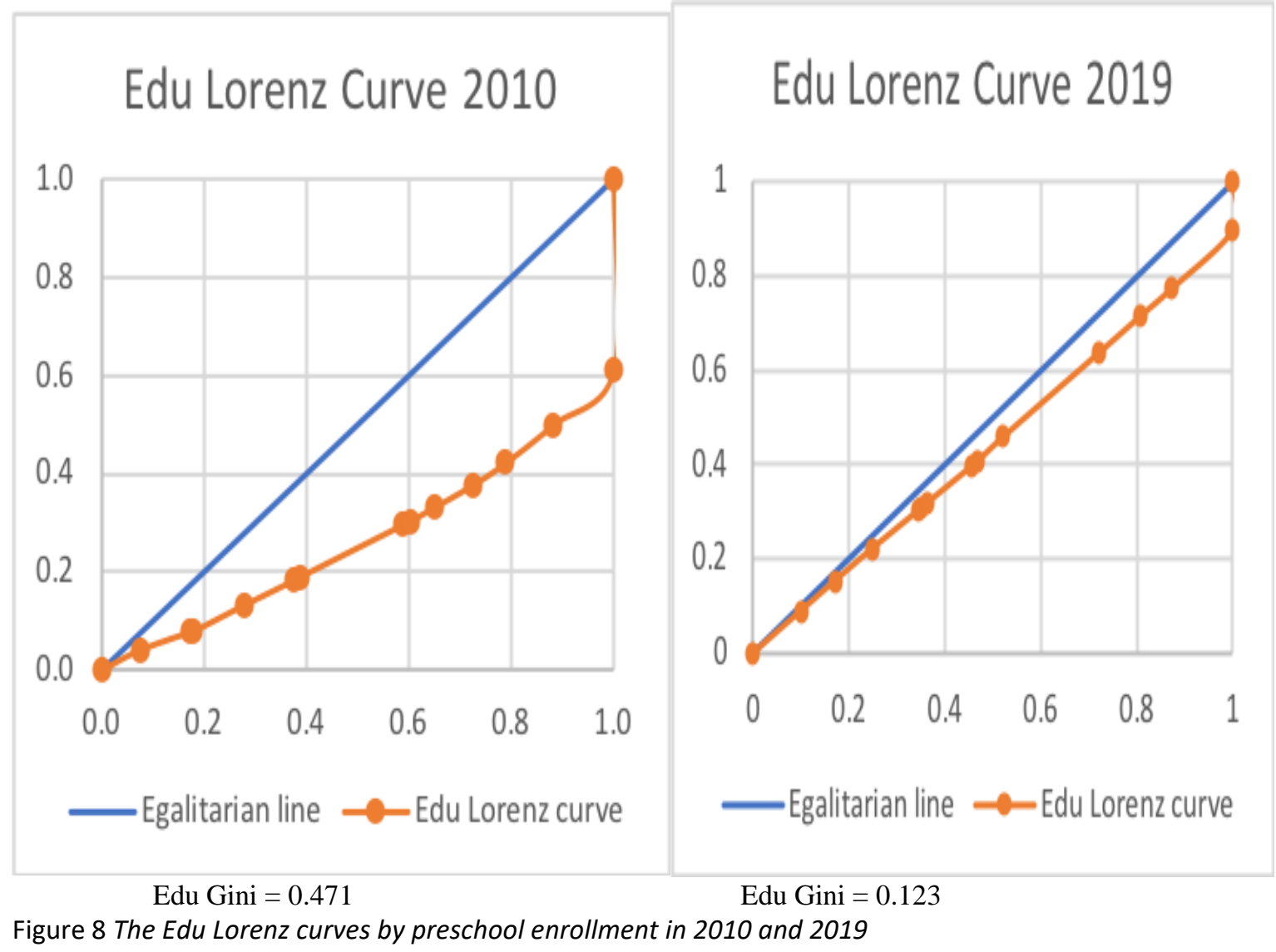

\subsection{Multiple regression estimates of the determinants of educational inequality}

According to the estimates shown in Table 2, government spending, books per child, faculty education attainment, and kindergarten densities are all positively correlated to preschool enrollment rate, while negatively correlated to educational inequality. That is to say, when the intermediate factors increase, the preschool enrollment rate increases, and educational inequality improves.
Due to restrictions in collecting data on the provincial EduGini index, the national EduGini index is the same for all sample provinces in a given year. On the contrary, preschool enrollment rates differ for all provinces in a year. Therefore, using preschool enrollment as the dependent variable is more reasonable in estimating the causes. By comparing coefficients, increasing faculty education attainment is the most significant cause of reduction in educational inequality and improvement in preschool enrollment. 
Table 2 Multiple linear regression estimates on intermediate factors

\begin{tabular}{|c|c|c|c|c|c|c|c|c|}
\hline \multirow{3}{*}{$\begin{array}{l}\text { govt } \\
\text { spending }\end{array}$} & \multicolumn{4}{|c|}{ EduGini index } & \multicolumn{4}{|c|}{ preschool enrollment rate } \\
\hline & $-0.089 * * *$ & $-0.013 * * *$ & $-0.047 * *$ & $-0.078 * * *$ & $0.240 * * *$ & $0.109^{* * *}$ & $0.136 * * *$ & $0.151^{* * * *}$ \\
\hline & $(0.021)$ & $(0.019)$ & $(0.018)$ & $(0.023)$ & $(0.033)$ & $(0.029)$ & $(0.031)$ & $(0.027)$ \\
\hline \multirow{2}{*}{$\begin{array}{l}\text { books per } \\
\text { child }\end{array}$} & & $-0.023 * * *$ & $-0.012 * * *$ & $-0.013 * *$ & & $0.040^{* * * *}$ & $0.031 * * *$ & $0.019^{* * * *}$ \\
\hline & & $(0.003)$ & $(0.003)$ & $(0.005)$ & & (0.004) & $(0.005)$ & $(0.005)$ \\
\hline \multirow{2}{*}{$\begin{array}{l}\text { faculty edu } \\
\text { attainment }\end{array}$} & & & $-0.764 * * *$ & $-1.085^{* * *}$ & & & $0.585^{* *}$ & $0.576^{* * *}$ \\
\hline & & & $(0.139)$ & $(0.179)$ & & & $(0.234)$ & $(0.208)$ \\
\hline \multirow{2}{*}{$\begin{array}{l}\text { kindergarten } \\
\text { density }\end{array}$} & & & & $-0.015 * * *$ & & & & $0.024 * * *$ \\
\hline & & & & $(0.003)$ & & & & $(0.004)$ \\
\hline R square & 0.127 & 0.435 & 0.545 & 0.612 & 0.292 & 0.576 & 0.596 & 0.684 \\
\hline
\end{tabular}

The DD estimates and multiple linear regression results suggest that faculty quality and kindergarten density are not only affected by the free preschool education policy, but also influence educational inequality and preschool enrollment. However, the policy does not affect government spending and books per child, the other two determinants of educational inequality. Therefore, we can conclude that the policy increases enrollment rates and decreases educational inequality through improving faculty quality and kindergarten accessibility. Moreover, the government could invest in education and increase individual school resources, as they also help reduce inequality.

\subsection{Checking educational inequality with the Chi- square test}

Finally, the Chi-square test uses actual enrollment as the observed distribution and $100 \%$ for all provinces as the theoretical distribution. The results of the Chi-square tests using Eq. (5) are shown in Table 3. The null hypothesis that all provinces have an enrollment rate of $100 \%$ was rejected from 2010 to 2018 with a significance level of $5 \%$. Therefore, there was not absolute educational equality before 2018, and educational inequality did exist. However, in 2019, the p-value is greater than 5\%, so the null hypothesis cannot be rejected.

Table 3Chi-square statistics, 2010-2019

\begin{tabular}{|c|c|c|c|c|c|c|c|c|c|c|}
\hline & 2010 & 2011 & 2012 & 2013 & 2014 & 2015 & 2016 & 2017 & 2018 & 2019 \\
\hline Chi-sauare & $265.51 * *$ & $212.072 *$ & $158.335^{*}$ & $125.425 *$ & $97.966 *$ & $82.907^{*}$ & $59.707 * *$ & $37.046 *$ & \multicolumn{2}{|l|}{$25.055^{*}$} \\
\hline Cni-square & $*$ & $* *$ & $* *$ & $* *$ & $* *$ & $* *$ & $*$ & $* *$ & $*$ & 16.948 \\
\hline df & 12 & 12 & 12 & 12 & 12 & 12 & 12 & 12 & 12 & 12 \\
\hline p-value & 0.000 & 0.000 & 0.000 & 0.000 & 0.000 & 0.000 & 0.000 & 0.000 & 0.015 & 0.152 \\
\hline
\end{tabular}

Note. $*, * *, * * *$ represent significance at $10 \%, 5 \%$, and $1 \%$ level, respectively.

By comparing the proportion of individual Chi-square in the total Chi-square, we are able to rank the provinces that contribute the most to educational inequality. Fig. 9 shows the contributions of different provinces in 2010 and 2019. In 2010, Tibet contributed $21.46 \%$ of the total Chi-square, followed by Yunnan (14.74\%), Ningxia (8.88\%), and Jiangxi (8.72\%). In 2019, Jiangxi made the most contribution (15.62\%), followed by Yunnan $(14.6 \%)$, Tibet $(14.32 \%)$, and Ningxia (10.99\%). This implies that the free preschool educational policy has accurately targeted Tibet, one of the most unequal provinces in 2010, and has successfully increased its enrollment rate, indicated by a reduction in its Chi-square contribution. However, other provinces without free preschool education, including Yunnan and Ningxia, contribute more over the years. Therefore, implementing similar policies in these regions might further reduce educational inequality. 


\section{Chi-square Contribution 2010 Unit: \%}

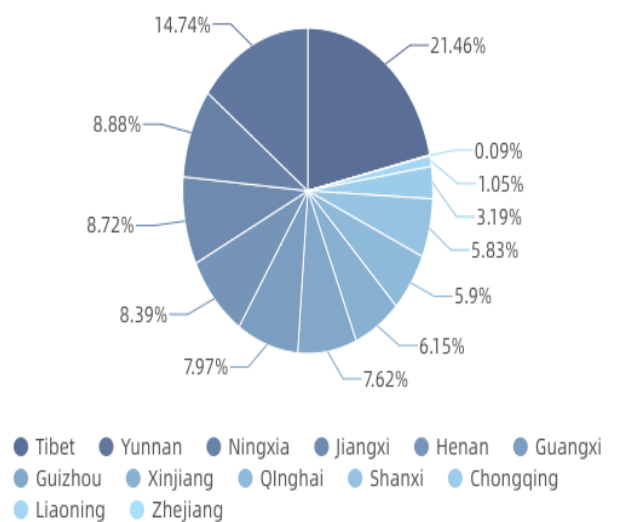

Chi-square Contribution 2019 Unit: \%

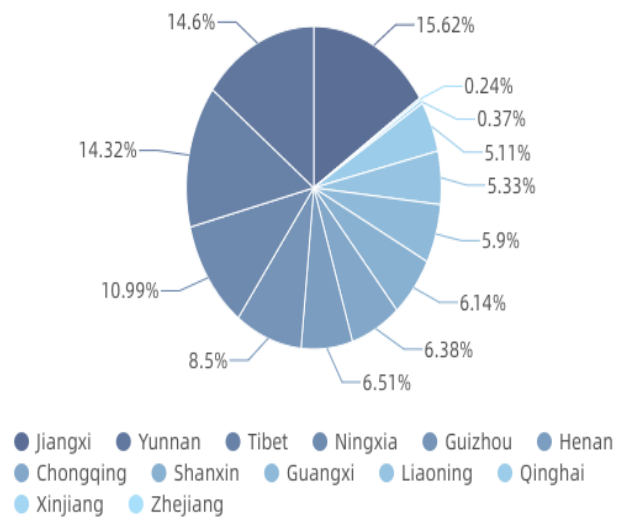

Figure 9 Contributions of different provinces' Chi-squares in 2010 and 2019

\section{CONCLUSION}

According to human capital theory (T.W Schulitz), the return on investment for pre-school education far exceeds that for other school and vocational training. In this paper, the authors discuss the impact of the free preschool education policy in Tibet on educational inequality across thirteen provinces in China. The results show that the policy has a positive impact on reducing educational inequality among provinces by improving teachers' education attainment and increasing kindergarten density. Hence, the key to solving educational inequality is to improve the quality and quantity of some school resources like faculty and books.

Moreover, free education policies should prioritize disadvantaged children in underdeveloped areas, because the provinces that contribute to educational inequality the most are Tibet, Yunnan, and Ningxia, which are all located in Western China with stagnant economic development. Therefore, similar preschool education policies in these regions might alleviate educational and income inequality.

In conclusion, the free preschool education policy in Tibet has reduced inequality in educational opportunities through improving faculty quality and kindergarten density. Implementing the policy in other underdeveloped regions like Ningxia and Yunnan might reduce educational inequality furthermore. Meanwhile, government expenditure on education might be more effective if the government recruits and subsidizes highquality preschool teachers. Future research could identify more intermediate factors such as government expenditures specifically on preschool. The education gap between urban and rural areas within a province is also worth noticing. Therefore, researchers could also calculate the EduGini index at the provincial level and test the direct effect of free preschool education on educational inequality.

\section{REFERENCES}

[1] Qiu, y. (1988). A brief introduction and preliminary evaluation of the theory of human capital in education investment. Heilongjiang province higher education research, 120-127. Doi: CNKI: SUN: HLJG. 0.1988-02-028.

[2] Heckman J J. Skill formation and the economics of investing in disadvantaged Children[J]. Science, 2006, 312(5782):1900-1902.

[3] Elango, S., J. L. García, J. J. Heckman and A. Hojman (2015), "Early Childhood Education", IZA Discussion Paper no. 9476.

[4] Reynolds, A.J. et al. Age 21 Cost-Benefit Analysis of the Title I Chicago Child-Parent Centers. Institute for Research on Poverty Discussion Paper no. 124502 (2002).

[5] Gu Quan.(2017). Characteristics and implications of Preschool education welfare policy in Finland. Guangdong economy.

[6] Hao Xiaochuan. (2014). Policy process analysis of free preschool education. Nanjing Normal University.

[7] Garces, E., Thomas, D., \& Currie, J. (2000, December 1). Longer term effects of head start. NBER.

https://www.nber.org/papers/w8054.

[8] Wang Yuchao.(2011). Unfair Status quo of Preschool education and ways to improveit.Journal of Anqing teachers college (social science edition), 130-133. Doi: CNKI:SUN: AQSS.0.2011-06-032.

[9] Song, Wei. "Xinjiang Increases Support for Preschool Education." China Daily, 18 Feb. 2014. www.chinadaily.com.cn/china/201402/18/content_17289668.htm.

[10] Wei Jun, Song Yan.(2012). Research on regional balanced development of Preschool education in China from the perspective of education equity. 
Education Tribune: the second half, 12-16. Doi: 10.3969/j.issn.1005-3476-B.2011.09.004.

[11] Snow, John. (1849). On the Mode of Communication of Cholera. John Churchill.

[12] Meer, J., \& West, J. (2015). Effects of the minimum wage on employment dynamics. Journal of Human Resources, 51(2), 500-522. https://doi.org/10.3368/jhr.51.2.0414-6298r1

[13] Li, H., Graham, D. J., \& Majumdar, A. (2012). The effects of congestion charging on road traffic casualties: A causal analysis using difference-indifference estimation. Accident Analysis \& Prevention, 49, 366-377. doi:10.1016/j.aap.2012.02.013

[14] Dimick JB, Ryan AM. Methods for Evaluating Changes in Health Care Policy: The Difference-inDifferences Approach. JAMA. 2014;312(22):24012402. doi:10.1001/jama.2014.16153

[15] Cao, Z., \& Song, X. (2011). SB1 comparison OF Difference-in-difference, propensity Score matching and instrumental variables in estimating cost differences between two cohorts. Value in Health, 14(3).

https://doi.org/10.1016/j.jval.2011.02.025

[16] Goodman-Bacon, A. (2018, September 10). Difference-in-differences with variation in treatment timing. NBER. https://www.nber.org/papers/w25018

[17] Wen Zhu.(2011). Inequity in preschool education in China and solution. Journal of Shanxi institute of education, $46 \quad$ to 48. Doi:CNKI:SUN:SHAA.0.2011-04-010.

[18] Thomas, V., Wang, Y., \& Fan, X. (2001). Measuring education inequality: Gini coefficients of education. Policy Research Working Papers. https://elibrary.worldbank.org/doi/abs/10.1596/181 3-9450-2525.

[19] Li Jing yao(2021). Research on the development of education equity in China: Calculation and analysis based on Gini coefficient. Journal of Weifang Vocational College of Engineering (02),19-24. doi:CNKI:SUN:WFJY.0.2021-02-004.

[20] Yao Jijun(2009). The evolution of Educational equality in China: An estimation based on the Gini coefficient of education (1949-2006). Science in Education (01),14-17. doi:CNKI:SUN: JYKO.0.2009-01-004.

[21] Banzragch, O., Mizunoya, S., \& Bayarjargal, M. (2019, May 21). Education inequality IN Mongolia: Measurement and causes. International Journal of Educational Development. https://www.sciencedirect.com/science/article/pii/S 0738059318303687.

[22] Wang, J.(2004). Factors influencing the increase of primary school enrolment rate in China. The Shaoxing university journal(natural science), 100103+113. Doi: CNKI: SUN: SXWL.0.2004-08024.
[23] She Yan.(2012). The Influence of family on Children's preschool Education. Science and education wenhui (ten-day), 85 + 89.Doi: CNKI: SUN: KJWZ.0.2012-12-046.

[24] Jin Yipin.(2012). Analysis of the impact of family education on preschool education. New course (social), $65 . \quad$ Doi:10.3969/j.issn.1674697X.2012.08.069.

[25] Sun, Shaohua. "The Central Government Allocates 173.93 Billion Yuan in Urban and Rural Compulsory Education Subsidies." Xinhuanet, 19 May 2021, www.xinhuanet.com/politics/202105/19/c_1127462625.htm.

[26] Plackett, R. L. (1983). Karl Pearson and the chisquared test. International Statistical Review / Revue Internationale De Statistique, 51(1), 59. https://doi.org/10.2307/1402731 